
indígenas. Revista Eletrônica Direito e Política, Programa de Pós-Graduação Stricto Sensu em Ciência Jurídica da UNIVALI, Itajaí, v.11, n.2, 2o quadrimestre de 2016. Disponível em: www.univali.br/direitoepolitica - ISSN 1980-7791.

\title{
INFLUÊNCIAS DO DIREITO AMBIENTAL NOS DIREITOS INDÍGENAS
}

INFLUENCES OF ENVIRONMENTAL LAW ON INDIGENOUS RIGHTS

\author{
Alisson de Bom de Souza ${ }^{1}$ \\ Loreno Weissheimer ${ }^{2}$
}

SUMÁRIO: Introdução. 1. Breves notas sobre o direito dos índios à diferença. 2. Direito ambiental como paradigma de sustentabilidade. 3. Aplicação das normas ambientais em terras indígenas. 4. O caso da sobreposição de terras indígenas em unidades de conservação ambiental. Considerações finais. Referências das fontes citadas.

\section{RESUMO}

Este artigo discute a aplicação do direito ambiental e do paradigma da sustentabilidade nos direitos dos índios previstos na Constituição da República Federativa do Brasil de 1988. Para tanto, apresentam-se noções gerais do direito dos índios à diferença, bem como sobre direito ambiental e sustentabilidade. O objetivo é analisar a influência do direito ambiental nas terras tradicionalmente ocupadas pelos índios, verificando potenciais conflitos e indicando a aproximação entre sustentabilidade e terras indígenas. A metodologia aplicada é a indutiva. Utiliza-se, também, as técnicas do referente, da categoria, do conceito operacional e da pesquisa bibliográfica.

PALAVRAS-CHAVE: Direito ambiental; Sustentabilidade; Direitos indígenas; Terras indígenas.

\footnotetext{
1 Mestrando em Ciência Jurídica na Universidade do Vale do Itajaí (UNIVALI). Especialista em Direito Público pela UNIVALI-ESMAFESC e Especialista em Direito Constitucional pela UNISUL-LFG. Graduado em Direito pela Universidade Federal de Santa Catarina (UFSC). Procurador do Estado de Santa Catarina. e-mail: alisson@pge.sc.gov.br.

2 Mestrando em Ciência Jurídica na Universidade do Vale do Itajaí (UNIVALI). Especialista em Direito Tributário pela UFSC. Graduado pela Pontifícia Universidade Católica do Rio Grande do Sul (PUC/RS). Procurador do Estado de Santa Catarina. email: loreno@pge.sc.gov.br.
} 
SOUZA, Alisson de Bom de. WEISSHEIMER, Loreno. Influências do direito ambiental nos direitos indígenas. Revista Eletrônica Direito e Política, Programa de Pós-Graduação Stricto Sensu em Ciência Jurídica da UNIVALI, Itajaí, v.11, n.2, 2o quadrimestre de 2016. Disponível em: www.univali.br/direitoepolitica - ISSN 1980-7791.

\section{ABSTRACT}

This article discusses the application of environmental law and sustainability paradigm in the land rights of Indians provided for in the Constitution of the Federative Republic of Brazil of 1988. Therefore, we present general notions of the right of the Indians to the difference, as well as on environmental law and sustainability. The objective is to analyze the influence of environmental law in the lands traditionally occupied by Indians, checking potential conflicts and indicating the approach of sustainability and indigenous lands. The applied methodology is inductive. Also to use the techniques of the referent, category, the operational concept and bibliographic research.

\section{KEYWORDS}

Environmental law; sustainability; Indigenous rights; indigenous Lands.

\section{INTRODUÇÃO}

A necessidade de preservação do meio ambiente e do uso sustentável dos recursos naturais para as gerações atuais e futuras é um tema de gradativa consolidação científica, além de nas últimas décadas ter ganhado força nas mais relevantes discussões sociais.

Por outro lado, a Constituição da República Federativa do Brasil de 1988, no artigo 231, garante aos índios o direito originário à posse permanente das terras que tradicionalmente ocupam e à proteção dos seus usos, tradições e costumes.

A questão se coloca em face ao que prescreve o $\S 2^{\circ}$, do artigo 231, da Constituição de 1988: "As terras tradicionalmente ocupadas pelos índios destinam-se a sua posse permanente, cabendo-Ihes o usufruto exclusivo das riquezas do solo, dos rios e dos lagos nelas existentes".

O problema que surge é o aparente conflito entre o direito dos índios a manejar as riquezas naturais de suas terras conforme seus costumes 

indígenas. Revista Eletrônica Direito e Política, Programa de Pós-Graduação Stricto Sensu em Ciência Jurídica da UNIVALI, Itajaí, v.11, n.2, 2o quadrimestre de 2016. Disponível em: www.univali.br/direitoepolitica - ISSN 1980-7791.

e o arcabouço normativo do direito ambiental, que visa proteger o meio ambiente.

Pretende-se demonstrar, a partir da interpretação doutrinária e jurisprudencial, que o usufruto exclusivo, pelos índios, das riquezas do solo, dos rios e dos lagos das terras que tradicionalmente ocupam deve se realizar de forma sustentável com vistas ao interesse das atuais e futuras gerações.

O objetivo deste artigo é verificar a aplicação do arcabouço jurídicoambiental às práticas tradicionais dos indígenas em suas terras. 0 trabalho será desenvolvido em quatro tópicos, sendo que no primeiro apresentar-se-á o direito dos índios à diferença; no segundo, demonstrar-se-á, em linhas gerais, o núcleo do direito ambiental e o paradigma da sustentabilidade; no terceiro, por sua vez, verificar-seá a aplicação do direito ambiental nas terras indígenas; e, por fim, no quarto capítulo, se analisará a possibilidade de sobreposição de terra indígena em unidade de preservação ambiental.

Quanto à metodologia, o relato dos resultados será composto na base lógica indutiva. Nas diversas fases da Pesquisa, serão utilizadas as técnicas do referente, da categoria, do conceito operacional e da pesquisa bibliográfica ${ }^{3}$.

\section{BREVES NOTAS SOBRE O DIREITO DOS ÍNDIOS À DIFERENÇA}

A par do direito à igualdade, já consagrado Princípio Constitucional, o direito à diferença ganhou destaque com a Constituição Federal de 1988, no escopo de se respeitar a alteridade e para que ocorra a

\footnotetext{
3 PASOLD, Cesar Luiz. Metodologia da pesquisa jurídica: Teoria e prática. $12^{a}$
} ed. São Paulo: Conceito editorial, 2011. 
SOUZA, Alisson de Bom de. WEISSHEIMER, Loreno. Influências do direito ambiental nos direitos indígenas. Revista Eletrônica Direito e Política, Programa de Pós-Graduação Stricto Sensu em Ciência Jurídica da UNIVALI, Itajaí, v.11, n.2, 2o quadrimestre de 2016. Disponível em: www.univali.br/direitoepolitica - ISSN 1980-7791.

promoção de direitos de grupos minoritários, diante da existência de diferenças naturais e culturais que precisam ser preservadas.

Ao discorrer sobre o direito à igualdade Márcia Villas Boas comenta:

O princípio constitucional da igualdade confirma as conquistas estampadas na Declaração dos Direitos do Homem e do Cidadão (1789), que em seu art. 1.0, já assegurava que "Os homens nascem e permanecem livres e iguais em direitos." Quando se fala em igualdade, o que deve imperar é a justiça, na medida em que devem ser limitadas, a todo custo, as arbitrariedades, o excesso de poder e, no caso dos povos indígenas, evitando-se o etnocídio e a consequente degradação de sua história. ${ }^{4}$

O direito à diferença é reconhecido aos índios por expressa previsão do artigo 231, caput, da Constituição Federal de 1988: "São reconhecidos aos índios sua organização social, costumes, línguas, crenças e tradições $[\ldots]^{\prime \prime}$.

Assim como garante a todos os brasileiros o pleno exercício e acesso às fontes da cultura nacional, previsto pelo artigo 215, caput, da Constituição, o $\S 10$ protege as manifestações culturais próprias:

Art. 215. O Estado garantirá a todos o pleno exercício dos direitos culturais e acesso às fontes da cultura nacional e apoiará e incentivará a valorização e a difusão das manifestações culturais.

$\S 10$ O Estado protegerá as manifestações das culturas populares, indígenas e afro-brasileiras, e das de outros grupos participantes do processo civilizatório nacional.

A Constituição Federal de 1988 deu atenção especial aos povos indígenas, reconhecendo sua organização social, línguas, cultura,

\footnotetext{
4 VILAS BOAS, Márcia Cristina Altvater. Os povos indígenas brasileiros e a transição paradigmática: da integração à interação. Porto Alegre: Núria Fabris, 2012. p. 57.
} 
SOUZA, Alisson de Bom de. WEISSHEIMER, Loreno. Influências do direito ambiental nos direitos indígenas. Revista Eletrônica Direito e Política, Programa de Pós-Graduação Stricto Sensu em Ciência Jurídica da UNIVALI, Itajaí, v.11, n.2, 2o quadrimestre de 2016. Disponível em: www.univali.br/direitoepolitica - ISSN 1980-7791.

visões de mundo, religiões, modos de vida, peculiares a cada grupo ou povo.

A mudança de paradigma teve por finalidade preservar a cultura e os povos indígenas, já que a política integracionista acabava degradando e diminuindo as populações indígenas, como comenta Márcia Vilas Boas:

A política integracionista, da forma como vinha sendo realizada, acabava por forçar um contato entre índios e não índios para o qual os mesmos não estavam preparados. Os não índios não sabiam conviver com uma cultura tão diferente como a indígena. Já os índios, forçados a integrar-se à sociedade nacional, a assumir obrigações para as quais também não haviam sido preparados, acabavam refugiando-se, muitas vezes, até mesmo no álcool e em outros vícios e, assim, a cultura indígena, aos poucos, ia se degradando, e a população indígena diminuindo assustadoramente. ${ }^{5}$

Nessa linha de superação do paradigma integracionista leciona Villares:

Os grupos étnicos são reconhecidos como tais pelo direito e deverão ter suas culturas protegidas e seus direitos assegurados, devendo-se abandonar qualquer idéia de integração forçada a uma unicidade étnica ou cultural. ${ }^{6}$

A partir do novo marco constitucional, portanto, deve-se abandonar qualquer ideia de integração forçada a uma unicidade étnica ou cultural, garantindo-se o direito dos índios à diferença.

5 VILAS BOAS, Márcia Cristina Altvater. Os povos indígenas brasileiros e a transição paradigmática: da integração à interação. p. 68.

6 VILLARES, Luiz Fernando. Direito e povos indígenas. Curitiba: Juruá, 2009. p. 17. 

indígenas. Revista Eletrônica Direito e Política, Programa de Pós-Graduação Stricto Sensu em Ciência Jurídica da UNIVALI, Itajaí, v.11, n.2, 2o quadrimestre de 2016. Disponível em: www.univali.br/direitoepolitica - ISSN 1980-7791.

\section{DIREITO AMBIENTAL COMO PARADIGMA DE SUSTENTABILIDADE}

Desde a Conferência das Nações Unidas sobre o Meio Ambiente Humano, realizada na cidade de Estocolmo, no ano de 1972, uma das questões dizia respeito aos conflitos econômicos entre os países pobres e países ricos, diretamente entre proteção ao meio ambiente e direito ao desenvolvimento, para muitos considerados opostos.

Já na Conferência das Nações Unidas sobre o Meio Ambiente e Desenvolvimento realizada na cidade do Rio de Janeiro, no ano de 1992, a expressão "desenvolvimento sustentável" começou a se tornar popular.

No enunciado 3 da Declaração do Rio de Janeiro consta: "O direito ao desenvolvimento deve ser realizado de modo a satisfazer as necessidades relativas ao desenvolvimento e ao meio ambiente das gerações presentes e futuras".

Em comentário, Boff adverte que, para os analistas, a contradição existente entre a lógica do desenvolvimento do tipo capitalista e entre a dinâmica do meio ambiente, que se rege pelo equilíbrio, fica cada vez mais clara:

Para os analistas ficava cada vez mais clara a contradição existente entre a lógica do desenvolvimento de tipo capitalista, que sempre procura maximalizar os lucros às expensas da natureza, criando grandes desigualdades sociais (injustiças), e entre a dinâmica do meio ambiente, que se rege pelo equilíbrio, pela interdependência de todos com todos e pela reciclagem de todos os resíduos (a natureza não conhece lixo) ${ }^{7}$.

\footnotetext{
7 BOFF, Leonardo. Sustentabilidade: 0 que é, o que não é. 2. ${ }^{a}$ Ed. - Petrópolis, RJ: Vozes, 2013. p. 35.
} 

indígenas. Revista Eletrônica Direito e Política, Programa de Pós-Graduação Stricto Sensu em Ciência Jurídica da UNIVALI, Itajaí, v.11, n.2, 2o quadrimestre de 2016. Disponível em: www.univali.br/direitoepolitica - ISSN 1980-7791.

A Constituição Federal de 1988, no caput do artigo 225, dispõe que compete ao Poder Público e à coletividade o dever de defender e preservar o meio ambiente para as gerações presentes e futuras.

Sustentabilidade, do ponto de vista ecológico, consiste nos recursos naturais existentes numa sociedade, que representam a capacidade natural de suporte às ações empreendedoras locais; do ponto de vista político a sustentabilidade é representada pela capacidade de a sociedade se organizar por si própria.

O objetivo principal da legislação de proteção ambiental é a sustentabilidade ecológica, consoante leciona Édis Milaré:

Com efeito, a partir de nível máximo hierárquico da Constituição Federal até os atos menores (como resoluções, regulamentos e portarias), passando pelo conjunto da legislação infraconstitucional e decretos regulamentares relativos ao meio ambiente, fica evidenciada a solicitude do legislador e do administrador público com a preservação do meio, com a qualidade ambiental e a qualidade de vida humana, com o manejo acertado dos recursos ambientais. A Política Nacional do Meio Ambiente e a legislação por ela inspirada não deixam margem à dúvidas. No seu âmbito próprio, as Resoluções do CONAMA (Conselho Nacional do Meio Ambiente) propugnam, de várias formas, a sustentabilidade dos elementos do mundo natural. ${ }^{8}$

Para Gabriel Ferrer, a sustentabilidade foi construída a partir de uma dimensão tripla, ambiental, social e econômica, como equivalente a desenvolvimento sustentável:

Así, desde Johannesburgo se habla de sostenibilidad, em su triple dimensión, econômica, social y ambiental, como equivalente al DesarrolloSostenible. El desarrollo, pues,

8 MILARÉ, Édis. Direito do ambiente: a gestão ambiental em foco: doutrina, jurisprudência, glossário. $6^{a}$ Ed. rev., atual. eampl. São Pulo: Editora Revista dos Tribunais, 2009. p. 73. 
SOUZA, Alisson de Bom de. WEISSHEIMER, Loreno. Influências do direito ambiental nos direitos indígenas. Revista Eletrônica Direito e Política, Programa de Pós-Graduação Stricto Sensu em Ciência Jurídica da UNIVALI, Itajaí, v.11, n.2, 2o quadrimestre de 2016. Disponível em: www.univali.br/direitoepolitica - ISSN 1980-7791.

por muy adjetivado que sea, siguesiendoel paradigma que se propone. ${ }^{9}$

Segundo Ferrer, não é possível uma sustentabilidade parcial de comunidades regionais ou nacionais, à margem do que ocorre no planeta Terra. É necessário alcançar um pacto com a Terra, com o compromisso de manter os ecossistemas essenciais para a nossa sobrevivência como espécie, reformando os modos de produção e distribuição da riqueza, para acabar com as injustificáveis desigualdades. Ademais, é necessário construir novos modelos de governança que garantam a prevalência do interesse geral sobre individualismos, com a ciência e a técnica a serviço de um objetivo comum:

La consecución de uma sociedadsosteniblesupone, al menos que:

a) La sociedad que consideramos sea planetária, nuestro destino es común y no cabe La sostenibilidad parcial de unas comunidades nacionales o regionales al margem de lo que ocurra em el resto Del planeta. Construir uma comunidad global de cuidadanosactivos es indispensable para elprogreso de lasostenibilidad. Esta exigência exige, entre otras cosas, El superar La parcial visión "occidental" -y, si se me apura, meramente anglosajona-que tenemosdel mundo.

b) Alcancemos um pacto com La Tierra de modo que no comprometamos laposibilidad de mantienimento de losecosistemasesenciales que hacenposiblenuestra subsistência como espécie em unas condiciones ambientalesaceptables. Es imprecindiblereducirdrásticamentenuestra demanda y consumo de capital natural hasta alcanzar niveles razonables de reposición.

c) Seamoscapaces de alimentar y, mas aun, ofrecer una vida digna al conjunto de los habitantes del planeta,

9 FERRER, Gabriel Real. Sostenibilidad, Transnacionalidad y TransformacionesdelDerecho.In: ANTUNES, Maria Cláudia da Silva, GARCIA, Denise Schmitt Siqueira (Orgs.). Direito Ambiental. Transnacionalidade e Sustentabilidade. $1^{\text {a }}$ edição - dados eletrônicos. Itajaí: UNIVALI, 2013. Disponível em http://www.univali.br/ppcj/ebook. Acesso em 28.08.14. p. 10. 
SOUZA, Alisson de Bom de. WEISSHEIMER, Loreno. Influências do direito ambiental nos direitos indígenas. Revista Eletrônica Direito e Política, Programa de Pós-Graduação Stricto Sensu em Ciência Jurídica da UNIVALI, Itajaí, v.11, n.2, 2o quadrimestre de 2016. Disponível em: www.univali.br/direitoepolitica - ISSN 1980-7791.

acabando com injustificables desigualdades. Para ello es preciso reconsiderar y reformular los modos de producción y distribución de la riqueza. elhambre y lapobleza no sonsostenibles.

d) Recompongamos La arquitetura social de modo que acabemos com um modelo apresor que basa El confort y progreso de unas capas sociales em laexclusión sistemática de legiones de desfavorecidos,, huérfanos de cualquieroportunidad. Alcanzar um mínimo umbral de justica social es uma condiciónineluddible para caminarhacia La sostenibilidad.

e) Construamos nuevos modos de gobernanza que asegurenla prevalência delinteres general sobre individualismos insolidarios, seanéstos de indivíduos, corporacioines 0 estados. Se trata de politizar laglobalización, poniéndola al servicio de las personas y extendiendo mecanismos de gobiernobasados em nuevas formas de democracia de arquitetura asimétrica y basadas em La responsabilidad de los cuidados.

f) Pongamos la ciência y técnica al servicioel objetivo común. No solo losnuevosconocimentosdebenayudarnos a corregirerrorespasados, como por ejemplo mediante lacaptación de $\mathrm{CO} 2$, o a aportar soluciones eficaces a problemas como los que plantea uma civilización energético-dependiente, sino que indefectibllementelatecnologia disponible determina los modelos sociales em los que nos desarrollamos, tal como insistentemente demuestrala história. ${ }^{10}$

Nosso destino é comum e solidário, precisamos saber o que queremos e como alcançá-lo. Isso pressupõe novas formas de organização, conforme conclui Ferrer:

Alcanzar la sostenibilidad supone y exige transformar el mundo. El problema es que empezamos a saber lo que no queremos pero aún no sabemos exatamente lo que queremos ni, sobre todo, como conseguirlo. Em todo caso, esto es una evidencia, em la batalha por asegurar

10 FERRER, Gabriel Real. Sostenibilidad, Transnacionalidad y TransformacionesdelDerecho.In: ANTUNES, Maria Cláudia da Silva, GARCIA, Denise Schmitt Siqueira (Orgs.). Direito Ambiental. Transnacionalidade e Sustentabilidade. p. 14. 

indígenas. Revista Eletrônica Direito e Política, Programa de Pós-Graduação Stricto Sensu em Ciência Jurídica da UNIVALI, Itajaí, v.11, n.2, 2o quadrimestre de 2016. Disponível em: www.univali.br/direitoepolitica - ISSN 1980-7791.

el futuro del Planeta no habrá vencedores y vencidos. O todos ganamos, o todos perdemos. Nuestro destino es común, solidário. ${ }^{11}$

Assim, a necessidade de proteção ambiental na atualidade exige uma atuação sustentável dos atores políticos globais e locais, garantindo um meio ambiente equilibrado na atualidade e para as futuras gerações.

\section{APLICAÇÃO DAS NORMAS AMBIENTAIS EM TERRAS INDÍGENAS}

As normas de Direito Ambiental têm por escopo a proteção do meio ambiente em benefício das atuais e futuras gerações e significam, por conseguinte, uma interferência do Estado na conduta individual e coletiva dos cidadãos. Esse compromisso de sustentabilidade do Poder Público e da coletividade se dá por meio do controle das atividades de manejo do meio ambiente. Na lição de José Afonso da Silva:

As normas de Direito Ambiental imprimem enorme condicionamento às atividades humanas, visando a resguardar a qualidade do meio ambiente. 0 cumprimento desse condicionamento nem sempre é espontâneo. Por isso, a legislação prevê controles prévios, concomitantes e sucessivos, por parte de autoridade públicas, a fim de verificar a regularidade do exercício das atividades controladas. ${ }^{12}$

O relevante para este artigo é verificar se o fato de uma determinada comunidade indígena possuir usos, tradições e costumes não compatíveis com os condicionamentos expressos em normas ambientais suprime ou mitiga o seu âmbito de aplicação.

11 FERRER, Gabriel Real. Sostenibilidad, Transnacionalidad y TransformacionesdelDerecho.In: ANTUNES, Maria Cláudia da Silva, GARCIA, Denise Schmitt Siqueira (Orgs.). Direito Ambiental. Transnacionalidade e Sustentabilidade. p. 28.

12 SILVA, José Afonso da. Direito ambiental constitucional. 6 a ed. São Paulo: Malheiros, 2007. p. 279. 

indígenas. Revista Eletrônica Direito e Política, Programa de Pós-Graduação Stricto Sensu em Ciência Jurídica da UNIVALI, Itajaí, v.11, n.2, 2o quadrimestre de 2016. Disponível em: www.univali.br/direitoepolitica - ISSN 1980-7791.

Preliminarmente, a título de esclarecimento, não há dúvidas sobre a submissão dos indígenas às normas de direito ambiental fora dos limites de terra indígena tradicional ou mesmo em uma terra tradicional de etnia diversa.

Nota-se que o artigo 231, § 20 , da Constituição Federal de 1988, confere aos índios o usufruto exclusivo das riquezas do solo, dos rios e dos lagos existentes nas terras tradicionalmente ocupadas.

Há uma especial relação do indígena com os recursos ambientais encontrados nas terras tradicionalmente ocupadas. Villares expõe que "do meio ambiente, cuja base territorial é a terra indígena, os índios extraem os recursos ambientais necessários para suas atividades"13.

Por outro lado, alerta Villares:

Não se pode ignorar, no entanto, que alguns grupos indígenas cedem à exploração irregular de suas áreas, sendo que atividades como a extração de madeira, garimpo e arrendamento das terras para a agricultura e pecuária não são raras, muitas vezes até com a participação e o empreendedorismo dos próprios indígenas. ${ }^{14}$

O usufruto exclusivo não significa exploração irrestrita dos recursos naturais da terra indígena, ainda mais pelo valor essencial dos elementos solo e água para o meio ambiente, conforme ensinamento de José Afonso da Silva:

O solo - que, do ponto de vista ecológico, é constituído da camada da superfície da crosta terrestre, capaz de abrigar raízes de plantas - representa o substrato para a vegetação terrestre. É, assim, a terra vegetal, meio em

\footnotetext{
13 VILLARES, Luiz Fernando. Direito e povos indígenas. p. 214.

${ }^{14}$ VILLARES, Luiz Fernando. Direito e povos indígenas. p. 218.
} 
SOUZA, Alisson de Bom de. WEISSHEIMER, Loreno. Influências do direito ambiental nos direitos indígenas. Revista Eletrônica Direito e Política, Programa de Pós-Graduação Stricto Sensu em Ciência Jurídica da UNIVALI, Itajaí, v.11, n.2, 2o quadrimestre de 2016. Disponível em: www.univali.br/direitoepolitica - ISSN 1980-7791.

que se associam a litosfera, a hidrosfera e a atmosfera; é, pois, meio de sustentação da vida. ${ }^{15}$

A água é um bem indispensável à vida: humana, animal e vegetal. Compartilha dos processos ecológicos essenciais, como o da fotossíntese, o da quimiossíntese e o da respiração. Funciona como habitat e nicho ecológico de inúmeros organismos e espécies animais e vegetais. Sua mobilidade, seu poder de solubilidades, sua variação de densidade, sua característica de regulador térmico e especialmente sua tensão superficial são atributos que respondem por sua extraordinária função ecológica. ${ }^{16}$

Como afirma o Ministro Menezes Direito no seu voto no caso da Terra Indígena Raposa Serra do Sol:

Ao contrário do que sustentam alguns defensores de um caráter absoluto dos direitos indígenas, estes são, em verdade, uma das diversas expressões do interesse público de âmbito nacional. À nação brasileira interessa, sem dúvida, a proteção e a preservação dos interesses indígenas, mas interessa também a preservação do meio ambiente e da segurança de nossas fronteiras além de outros interesses públicos representados pela União, como prevê literalmente o art. 231 da Constituição da República. É importante identificar tais interesses para que o estatuto jurídico das comunidades indígenas possa ser de uma vez por todas definido considerando a disciplina constitucional. A identificação dos demais interesses públicos que poderão condicionar os direitos dos índios passa, em muitos casos pela edição de lei, ordinária ou complementar, ou pela autorização do Congresso Nacional. E em nossos dias é necessário ter presente que a preservação do meio ambiente é imperativa para a humanidade e não apenas para as nações ou comunidades individualmente consideradas. ${ }^{17}$ (grifou-se)

${ }^{15}$ SILVA, José Afonso da. Direito ambiental constitucional. p. 97.

16 SILVA, José Afonso da. Direito ambiental constitucional. p. 120

17 STF. Acórdão da Petição n. 3.388. Relator: Min. Carlos Britto. Tribunal Pleno. Julgado em 19-03-2009. Publicado no DJe em 01-07-2010. Disponível em http://redir.stf.jus.br/paginadorpub/paginador.jsp?docTP=AC\&docID $=612760$.

Acesso em 25.07.14. p. 176-177. 

indígenas. Revista Eletrônica Direito e Política, Programa de Pós-Graduação Stricto Sensu em Ciência Jurídica da UNIVALI, Itajaí, v.11, n.2, 2o quadrimestre de 2016. Disponível em: www.univali.br/direitoepolitica - ISSN 1980-7791.

Inclusive, a terra indígena tradicional não é de propriedade dos índios, mas sim bem da União, conforme o art. 20, XI, da Constituição, o que afasta ainda mais a hipótese de exploração irrestrita ou contrária às normas ambientais.

Registre-se, também, que não são todos os recursos naturais da terra indígena que são de usufruto dos índios. Villares explicita a questão:

Nem todos os recursos naturais das terras indígenas têm o índio como usufrutuário. Apenas as riquezas do solo, dos rios e dos lagos nelas existentes são de usufruto dos índios que as ocupam. O aproveitamento dos recursos hídricos, incluídos os potenciais energéticos, a pesquisa e a lavra de riquezas minerais em terras indígenas não seguem a norma de usufruto exclusivo, assim como não seguem o princípio do usufruto da propriedade privada. ${ }^{18}$

Os potenciais de energia hidráulica (art. 20, VIII, CF/88) e os recursos minerais (art. 20, IX, CF/88) são de propriedade da União sem distinção de estarem encravados em propriedade pública, particular ou terra indígena. Já os recursos hídricos podem ser bens da União (art. 20, III, CF/88) ou dos Estados (art. 26, I, II e III, CF/88) e por serem bens de importância social e estratégica, não são sujeitos a apropriação exclusiva.

O usufruto exclusivo não autoriza o índio a utilizar as riquezas naturais, especialmente o solo, os lagos e rios, em desrespeito às normas ambientais. A proteção dos costumes e tradições indígenas pela Constituição de 1988 protege a ampla utilização dos recursos ambientais da terra, desde que em consonância ao paradigma da sustentabilidade e às normas ambientais.

Por óbvio que o paradigma da sustentabilidade também se aplica aos índios, pois devem estar condicionados à proteção ambiental para

${ }^{18}$ VILLARES, Luiz Fernando. Direito e povos indígenas. p. 215. 

indígenas. Revista Eletrônica Direito e Política, Programa de Pós-Graduação Stricto Sensu em Ciência Jurídica da UNIVALI, Itajaí, v.11, n.2, 2o quadrimestre de 2016. Disponível em: www.univali.br/direitoepolitica - ISSN 1980-7791.

garantir o usufruto das riquezas naturais para as presentes e futuras gerações indígenas.

A rusga hermenêutica se encontra na possibilidade de o exercício das atividades típicas indígenas, tais como caça, pesca, agricultura de subsistência, pecuária, extrativismo e produção de artesanato sofrer restrições. Essas atividades devem ocorrer conforme as tradições seculares dos povos indígenas ou se submetem às obrigações ambientais a todos imposta?

A resposta necessita de um esclarecimento prévio. Os direitos fundamentais, dentre eles os relativos ao meio ambiente e os dos índios, não são absolutos. O sistema constitucional brasileiro adotou a teoria da relatividade dos direitos fundamentais. Para Alexandre de Moraes:

Os direitos humanos fundamentais não podem ser utilizados como um verdadeiro escudo protetivo da prática de atividades ilícitas, nem tampouco como argumento para afastamento ou diminuição da responsabilidade civil ou penal por atos criminosos, sob pena de total consagração ao desrespeito a um verdadeiro Estado de Direito. ${ }^{19}$

Ingo Sarlet indica no mesmo sentido:

[...] Considerando que nenhuma ordem jurídica pode proteger os direitos fundamentais de maneira ilimitada, a ideia de que os direitos fundamentais não são absolutos, no sentido de absolutamente blindados contra qualquer tipo de restrição na sua esfera subjetiva e objetiva, não tem oferecido maiores dificuldades, tendo sido, de resto, amplamente aceita no direito constitucional contemporâneo $[\ldots] .^{20}$

19 MORAES. Alexandre de. Direitos Humanos Fundamentais: teoria geral, comentários aos arts. $1^{\circ}$ a $5^{\circ}$ da Constituição da República Federativa do Brasil, doutrina e jurisprudência. 9a ed. São Paulo: Atlas, 2011. p. 27.

20 SARLET, Ingo Wolfgang. A eficácia dos direitos fundamentais: uma teoria geral dos direitos fundamentais na perspectiva contitucional. $10^{\mathrm{a}}$ ed. rev. atual. eampl. Porto Alegre: Livraria do Advogado, 2011. p. 387-388 

indígenas. Revista Eletrônica Direito e Política, Programa de Pós-Graduação Stricto Sensu em Ciência Jurídica da UNIVALI, Itajaí, v.11, n.2, 2o quadrimestre de 2016. Disponível em: www.univali.br/direitoepolitica - ISSN 1980-7791.

O ponto principal, portanto, é saber se as tradições e costumes indígenas na exploração dos recursos naturais são sustentáveis, pois o respeito à diversidade cultural, em princípio, não pode autorizar a prática predatória ao meio ambiente.

Se uma norma ambiental proíbe a pesca em determinada época do ano, analogicamente ao período de defeso, deve a comunidade indígena se submeter a esta regra, sob pena de cometimento de infração ambiental. Do mesmo modo, se determinada espécie animal corre risco de extinção, a proibição de sua caça deve ser respeitada também pelos índios, mesmo que nas tradições seculares de sua comunidade a caça daquela espécie fosse prática comum.

A Constituição de 1988 não apontou na direção da diferença na (i)legalidade, ou seja, o só fato de ser índio e sob pretexto de ser uma atividade tradicional, efetivada por gerações, permitir o tratamento diferenciado em relação ao cidadão não índio, que muitas vezes também pratica atividades que o seu pai, avô, bisavô praticavam. Se a atividade é contrária às restrições ambientais, aplica-se a normatividade vigente.

O dever da coletividade na preservação do meio ambiente, expressamente consignado no artigo 225 da Constituição Federal, engloba, também, os índios, pois esses pertencem a essa coletividade brasileira, enfim, "é dizer, povo brasileiro como um só continente humano de hoje, de ontem e de amanhã, a abarcar principalmente os três elementares grupos étnicos dos indígenas, do colonizador branco 

indígenas. Revista Eletrônica Direito e Política, Programa de Pós-Graduação Stricto Sensu em Ciência Jurídica da UNIVALI, Itajaí, v.11, n.2, 2o quadrimestre de 2016. Disponível em: www.univali.br/direitoepolitica - ISSN 1980-7791.

e da população negra"21. José Afonso da Silva explica o propósito constitucional de defesa do meio ambiente:

É nesse sentido que a Constituição prescreve que é dever do Poder Público e da coletividade defender e preservar o meio ambiente ecologicamente equilibrado para as presentes e futuras gerações (art. 225, caput). É igualmente nesse sentido que ela incumbe ao Poder Público preservar e restaurar os processos ecológicos essenciais e prover o manejo ecológico das espécies e ecossistemas, assim como preservar a diversidade e a integridade do patrimônio genético do país. "Preservar" e "restaurar" estão, aí, como formas de conservação que implicam manutenção e continuidade, que significam aproveitamento que garante a utilização perene e que protege os processos ecológicos e a diversidade genética, essenciais para a manutenção dos recursos ecológicos. ${ }^{22}$

O princípio da cooperação, conforme Cristiane Derani, "informa uma atuação conjunta do Estado e sociedade, na escolha de prioridades e nos processos decisórios" 23 .

Os índios não podem é sofrer perseguição pelos não índios por conta de sua cultura e tradição. Essa é a finalidade constitucional do art. 231 da Constituição. Eventual norma ambiental restringido especificamente - exercício de atividades quando executadas por índios é flagrantemente inconstitucional, porém quando há uma restrição ambiental geral, expressa como valor do paradigma da sustentabilidade, não podem os índios se furtar de a cumprir, prestigiando a proteção ambiental integral e a isonomia. $O$ Desembargador Federal Luiz de Lima Stefanini, mesmo apresentando crítica à escolha constitucional, assevera a submissão dos usos e costumes indígenas ao direito ambiental:

\footnotetext{
${ }^{21}$ STF. Acórdão da Petição n. 3.388. p. 40.

22 SILVA, José Afonso da. Direito ambiental constitucional. p. 89.

23 DERANI, Cristiane. Direito ambiental econômico. $3^{a}$ ed. São Paulo: Saraiva, 2008. p. 142.
} 

indígenas. Revista Eletrônica Direito e Política, Programa de Pós-Graduação Stricto Sensu em Ciência Jurídica da UNIVALI, Itajaí, v.11, n.2, 2o quadrimestre de 2016. Disponível em: www.univali.br/direitoepolitica - ISSN 1980-7791.

Particularmente e no momento atual os ocupantes de próprios da União, não sendo as aldeias terras devolutas (os sertões são devolutos), certo é que sobre elas não detêm hoje os índios aldeados direito individual, mas tão somente Ihes são deferidos os direitos à aldeia via usufruto restrito, expressão do acervo constitucional; delas não podem dispor segundo seus usos e costumes conforme examinado quando interceptado por um interesse público que a todos vincula. [...] A antinomia se expõe porque contempla a tutela dos valores indígenas ou bens jurídicos étnicos (uso do fogo para coivara, extração de bens da floresta, apreensão de espécimes nativos com objetivos diversos etc.) em contraste com a salvaguarda, no âmbito do direito ecológico e ambiental, que os tipificam como infrações civis e crimes contra a flora e a fauna. Proliferam no país exatamente por isso as contusões entre o uso das terras indígenas e os ortodoxos do meio ambiente. Não podem estes brasileiros explorar a madeira (que poderiam com sustentabilidade auferir significativamente resultados financeiros) em suas áreas demarcadas pelas mesmas restrições impostas aos demais brasileiros. ${ }^{24}$

Defender a utilização irrestrita dos recursos naturais no interior das terras indígenas tradicionais viola diretamente o princípio da isonomia. Índios e não índios são iguais, não havendo ferimento ao núcleo essencial da proteção constitucional à cultura indígena quando se restringe a utilização dos recursos naturais em conformidade às normas ambientais.

Além disso, não há, atualmente, diploma legal ou norma constitucional que estabeleça a discriminação ambiental em favor dos indígenas. Celso Antônio Bandeira de Mello é categórico ao afirmar que "se este intento não foi professado inequivocamente pela lei, embora de modo implícito, é intolerável, injurídica e inconstitucional qualquer

\footnotetext{
${ }^{24}$ STEFANINI, Luiz de Lima. Código indígena no direito brasileiro. $2^{a}$ ed. Curitiba: Juruá, 2012. p. 141.
} 

indígenas. Revista Eletrônica Direito e Política, Programa de Pós-Graduação Stricto Sensu em Ciência Jurídica da UNIVALI, Itajaí, v.11, n.2, 2o quadrimestre de 2016. Disponível em: www.univali.br/direitoepolitica - ISSN 1980-7791.

desequiparação que se pretenda fazer"25. Portanto, verifica-se a plena eficácia do direito ambiental nas terras indígenas tradicionais.

\section{O CASO DA SOBREPOSIÇÃO DE TERRAS INDÍGENAS EM UNIDADES DE CONSERVAÇÃO AMBIENTAL}

A própria tradição indígena tende a uma relação mais próxima com os elementos da natureza. Disso decorre a histórica fixação de comunidades indígenas em terras tradicionais de rica biodiversidade.

Esse contexto histórico e cultural explica o fato de muitas terras indígenas tradicionais em processo de reconhecimento ou já reconhecidas estarem encravadas em unidades de conservação ambiental.

A discussão que se colocou é a do aparente conflito entre a especial proteção dessas unidades ambientais e a demarcação de terras indígenas tradicionais.

Antes de responder o ponto central, as unidades de conservação são um dos tipos de espaços territoriais especialmente protegidos. José Afonso da Silva explica:

Espaços Territoriais Especialmente Protegidos são áreas geográficas públicas ou privadas (porção do território nacional) dotadas de atributos ambientais que requeiram sua sujeição, pela lei, a um regime jurídico de interesse público que implique sua relativa imodificabilidade e sua utilização sustentada, tendo em vista a preservação e proteção da integridade de amostras de toda a diversidade de ecossistemas, a proteção ao processo evolutivo das espécies, a preservação e proteção dos recursos naturais. ${ }^{26}$

25 MELLO, Celso Antônio Bandeira de. O conteúdo jurídico do princípio da igualdade. $3^{a}$ ed. São Paulo: Malheiros, 2010. p. 46.

${ }^{26}$ SILVA, José Afonso da. Direito ambiental constitucional. p. 232. 
SOUZA, Alisson de Bom de. WEISSHEIMER, Loreno. Influências do direito ambiental nos direitos indígenas. Revista Eletrônica Direito e Política, Programa de Pós-Graduação Stricto Sensu em Ciência Jurídica da UNIVALI, Itajaí, v.11, n.2, 2o quadrimestre de 2016. Disponível em: www.univali.br/direitoepolitica - ISSN 1980-7791.

De acordo com o artigo 20, I, da Lei n. 9.985/2000, as unidades de conservação são definidas como:

Art. $2^{\circ}$ Para os fins previstos nesta Lei, entende-se por:

I - unidade de conservação: espaço territorial e seus recursos ambientais, incluindo as águas jurisdicionais, com características naturais relevantes, legalmente instituído pelo Poder Público, com objetivos de conservação e limites definidos, sob regime especial de administração, ao qual se aplicam garantias adequadas de proteção;

Nos termos da lei, as unidades de conservação se dividem em dois grupos básicos: as unidades de proteção integral e as unidades de uso sustentável. As categorias das unidades de proteção integral são: estação ecológica, reserva biológica, parque nacional, monumento natural e refúgio da vida silvestre. Já as categorias das unidades de uso sustentável são: área de proteção ambiental, área de relevante interesse ecológico, floresta nacional, reserva extrativista, reserva de fauna, reserva de desenvolvimento sustentável e reserva particular do patrimônio natural.

O fundamento constitucional dos espaços especialmente protegidos é o art. $225, \S 10$, III, da Constituição Federal:

Art. 225. Todos têm direito ao meio ambiente ecologicamente equilibrado, bem de uso comum do povo e essencial à sadia qualidade de vida, impondo-se ao Poder Público e à coletividade o dever de defendê-lo e preservá-lo para as presentes e futuras gerações.

$\S 1^{0}$ - Para assegurar a efetividade desse direito, incumbe ao Poder Público:

$[\ldots]$

III - definir, em todas as unidades da Federação, espaços territoriais e seus componentes a serem especialmente protegidos, sendo a alteração e a supressão permitidas somente através de lei, 

indígenas. Revista Eletrônica Direito e Política, Programa de Pós-Graduação Stricto Sensu em Ciência Jurídica da UNIVALI, Itajaí, v.11, n.2, 2o quadrimestre de 2016. Disponível em: www.univali.br/direitoepolitica - ISSN 1980-7791.

\section{vedada qualquer utilização que comprometa a integridade dos atributos que justifiquem sua proteção;}

A Suprema Corte brasileira já decidiu pela perfeita compatibilidade entre as terras indígenas e o meio ambiente, inclusive no caso de ser envolvida área de conservação ambiental. O célebre julgamento do caso da Terra Indígena Raposa Serra do Sol delimitou o entendimento do STF sobre a temática. De início, a ementa do julgado já é esclarecedora:

15. A RELAÇÃO DE PERTINÊNCIA ENTRE TERRAS INDÍGENAS E MEIO AMBIENTE. Há perfeita compatibilidade entre meio ambiente e terras indígenas, ainda que estas envolvam áreas de "conservação" e "preservação" ambiental. Essa compatibilidade é que autoriza a dupla afetação, sob a administração do competente órgão de defesa ambiental. ${ }^{27}$

O Ministro Relator esmiúça o entendimento:

Índios e meio ambiente mantêm entre si uma natural relação de unha e carne. Não são como óleo e água, que não se misturam. Com o que de pronto ressai a seguinte compreensão das coisas: mais que uma simples relação de compatibilidade, o vínculo entre o meio ambiente e demarcação de terras indígenas é de ortodoxa pertinência. Razão pela qual o decreto homologatório das Terras Indígenas Raposa-Serra do Sol (antecipo o juízo) é inclusivo do Parque Nacional do Monte Roraima, conferindo-Ihe, redundantemente, aliás, uma dupla afetação: a ecológica e a propriamente indígena. ${ }^{28}$

A lei do Sistema Nacional de Unidades de Conservação, lei n. 9.985/00, prevê a possibilidade de sobreposição de unidades de conservação e outras áreas públicas, a exemplo das terras indígenas, sem qualquer

27 STF. Acórdão da Petição n. 3.388. p. 10.

${ }^{28}$ STF. Acórdão da Petição n. 3.388. p. 84. 

indígenas. Revista Eletrônica Direito e Política, Programa de Pós-Graduação Stricto Sensu em Ciência Jurídica da UNIVALI, Itajaí, v.11, n.2, 2o quadrimestre de 2016. Disponível em: www.univali.br/direitoepolitica - ISSN 1980-7791.

prejuízo à preservação do meio ambiente, conforme previsto em seu art. 26:

Art. 26. Quando existir um conjunto de unidades de conservação de categorias diferentes ou não, próximas, justapostas ou sobrepostas, e outras áreas protegidas públicas ou privadas, constituindo um mosaico, a gestão do conjunto deverá ser feita de forma integrada e participativa, considerando-se os seus distintos objetivos de conservação, de forma a compatibilizar a presença da biodiversidade, a valorização da sociodiversidade e o desenvolvimento sustentável no contexto regional.

No mesmo sentido, o Decreto n. $6.660 / 08$ prevê a possibilidade de práticas sustentáveis tradicionais mesmo em um dos biomas mais ameaçados do país, a Mata Atlântica, conforme se verifica do seu art. $2^{\circ}$ :

Art. $2^{\circ}$ A exploração eventual, sem propósito comercial direto ou indireto, de espécies da flora nativa provenientes de formações naturais, para consumo nas propriedades rurais, posses das populações tradicionais ou de pequenos produtores rurais, de que trata o art. $9^{\circ}$ da Lei no 11.428 , de 2006, independe de autorização dos órgãos competentes. (Grifou-se)

Nessa linha, cita-se, ainda, o Plano Estratégico Nacional de Áreas Protegidas (PNAP), Decreto n. 5.758/2006, que possui, entre suas diretrizes:"IX -assegurar os direitos territoriais das comunidades quilombolas e dos povos indígenas como instrumento para conservação de biodiversidade".

Do mesmo modo, o Decreto n. $7.747 / 2012$, que instituiu a Política Nacional de Gestão Territorial e Ambiental de Terras Indígenas, reconhece a possibilidade de compatibilização das terras indígenas com as unidades de conservação.

O Ministro Menezes Direito foi elucidativo no seu voto no Acórdão da Terra Indígenas Raposa Serra do Sol: 

indígenas. Revista Eletrônica Direito e Política, Programa de Pós-Graduação Stricto Sensu em Ciência Jurídica da UNIVALI, Itajaí, v.11, n.2, 2o quadrimestre de 2016. Disponível em: www.univali.br/direitoepolitica - ISSN 1980-7791.

\begin{abstract}
Nesse quadro, e considerando que o meio ambiente é um bem de todos os brasileiros, e também um bem da humanidade, a área da unidade de conservação, sujeita a tripla afetação (terra indígena, faixa de fronteira e parque nacional), deve ser administrada pelo órgão com atribuição para a gestão das unidades de conservação, o Instituto Chico Mendes de Conservação da Biodiversidade. Para tanto, deve contar com a participação das comunidades indígenas da área em caráter opinativo, que poderão ali transitar livremente podendo realizar exclusivamente atividades de extrativismo vegetal, caça e pesca nos períodos e condições estipulados pela administração, que deverá, contudo, levar em conta as tradições e costumes dos indígenas, podendo para tanto contar com a consultoria da FUNAI. Fica assegurado o trânsito de visitantes e pesquisadores nos horários e condições estipulados pela administração, tudo na perspectiva de preservação do ecossistema, o que quer dizer preservação da natureza como bem maior de toda a humanidade. ${ }^{29}$
\end{abstract}

A razão de todas essas normas é o reconhecimento da diferente relação ecológica que os povos indígenas mantêm com os recursos naturais. As comunidades indígenas tendem a ser aliadas do Poder Público e da sociedade na proteção do meio ambiente e dos espaços especialmente protegidos, tais como as unidades de conservação ambiental.

Se as unidades de conservação ambiental possuem fundamento constitucional e têm possibilidades restritas de utilização, por óbvio que não se pode conferir a determinado grupo social, no caso os índios, usufruto irrestrito de suas riquezas naturais.

O direito ao meio ambiente equilibrado é um direito fundamental de todos, já os direitos originários às terras tradicionalmente ocupadas são somente dos índios.

Parece razoável supor que no caso de sobreposição de áreas de unidades de conservação ambiental e terras indígenas prepondera a

${ }^{29}$ STF. Acórdão da Petição n. 3.388. p. 185. 

indígenas. Revista Eletrônica Direito e Política, Programa de Pós-Graduação Stricto Sensu em Ciência Jurídica da UNIVALI, Itajaí, v.11, n.2, 2o quadrimestre de 2016. Disponível em: www.univali.br/direitoepolitica - ISSN 1980-7791.

finalidade de proteção ambiental à finalidade de proteção indígena, porém isso não significa a obstrução ou supressão do direito originário dos índios às terras tradicionalmente ocupadas.

O que deve ficar claro, principalmente no processo demarcatório da terra indígena, é a certeza da identidade da etnia com a terra, pelo que o fato de estar encravada em unidade de conservação ambiental exige ainda maior rigor na análise pelos órgãos competentes. Priscila Silva Santos, em elucidativo artigo, arremata:

Exige-se, então, não somente uma mera afirmação por parte de uma etnia indígena, mas, uma comprovação da existência da identidade para com a terra que pretendem como sua. Logo, caso não se façam presentes essas evidências, não há que se falar em prioridade de ocupação para os índios, e sim na sua ilegitimidade para obter o domínio e a propriedade de dada terra. Na falta de elementos que denotem a certeza, cabe ao Estado cumprir sua função primordial de proteção ao meio ambiente. ${ }^{30}$

Portanto, é possível adequar a coexistência de um terra indígena em uma unidade de conservação ambiental, conquanto a proteção ambiental continue garantida pelos órgãos competentes.

\section{CONSIDERAÇÕES FINAIS}

Os direitos indígenas são o reconhecimento da sociedade brasileira a um conjunto de grupos étnicos diversificado nos costumes e tradições, mas sem sombra de dúvidas componente indissociável do povo brasileiro.

A especial proteção aos costumes e tradições indígenas traz à tona posições interpretativas que buscam eximir os índios de suas

30 SANTOS, Priscilla Silva. Conservação do Meio Ambiente ou Proteção das Comunidades Tradicionais Indígenas: o Dilema entre Direitos Fundamentais no Direito Ambiental Brasileiro. Revista Magister de Direito Ambiental e Urbanístico. Porto Alegre, v. 41 (abr./mai 2012). p. 80. 

indígenas. Revista Eletrônica Direito e Política, Programa de Pós-Graduação Stricto Sensu em Ciência Jurídica da UNIVALI, Itajaí, v.11, n.2, 2o quadrimestre de 2016. Disponível em: www.univali.br/direitoepolitica - ISSN 1980-7791.

responsabilidades perante a sociedade nacional, como que investidos no poder de ditar um Estado paralelo.

Demonstrou-se claramente que a temática ambiental e o dever-poder dos poderes públicos e de toda a sociedade, aí incluídos os indígenas, de proteção sustentável do meio ambiente para as presentes e futuras gerações são valores essenciais do Estado brasileiro.

É imprescindível que toda a sociedade adote a sustentabilidade como paradigma de utilização dos recursos naturais. O uso inadequado e abusivo dos recursos naturais não é e não pode ser permitido a qualquer dos componentes do povo brasileiro.

O direito dos índios ao exercício de seus usos, tradições e costumes não significa autorização para a utilização insustentável dos recursos naturais do meio ambiente. A aplicação das normas ambientais em terras indígenas é medida que se coaduna com uma interpretação harmonizadora do texto constitucional.

Aliado a isso, conforme decidido pelo STF no caso da Terra Indígena Raposa Serra do Sol, a existência de unidades de conservação ambiental não impede a demarcação de terras indígenas, porém os índios estão vinculados às restrições daquele espaço ambiental especialmente protegido.

Portanto, verifica-se a influência do direito ambiental nos direitos dos índios, pois estes são componentes da coletividade nacional e, conforme a Constituição de 1988, esta tem o dever de proteger o meio ambiente.

\section{REFERÊNCIAS DAS FONTES CITADAS}



indígenas. Revista Eletrônica Direito e Política, Programa de Pós-Graduação Stricto Sensu em Ciência Jurídica da UNIVALI, Itajaí, v.11, n.2, 2o quadrimestre de 2016. Disponível em: www.univali.br/direitoepolitica - ISSN 1980-7791.

BOFF, Leonardo. Sustentabilidade: O que é: o que não é. 2. ${ }^{a}$ Ed. Petrópolis, RJ: Vozes, 2013.

DERANI, Cristiane. Direito ambiental econômico. $3^{a}$ ed. São Paulo: Saraiva, 2008.

FERRER, Gabriel Real. Sostenibilidad, Transnacionalidad y TransformacionesdelDerecho. In: ANTUNES, Maria Cláudia da Silva, GARCIA, Denise Schmitt Siqueira (Orgs.). Direito Ambiental. Transnacionalidade e Sustentabilidade. $1^{\text {a }}$ edição - dados eletrônicos. Itajaí: UNIVALI, 2013. Disponível em http://www.univali.br/ppcj/ebook. Acesso em 28.08.14.

INSTITUTO BRASILEIRO DE GEOGRAFIA E ESTATÍSTICA (IBGE). Censo Demográfico 2010. Características Gerais dos Indígenas - Resultados do Universo. Disponível em ftp://ftp.ibge.gov.br/Censos/Censo_Demografico_2010/Caracteristica s_Gerais_dos_Indigenas/pdf/Publicacao_completa.pdf. Acesso em 25 de jun. 2014.

MELLO, Celso Antônio Bandeira de. O conteúdo jurídico do princípio da igualdade. $3^{a}$ ed. São Paulo: Malheiros, 2010.

MILARÉ, Édis. Direito do ambiente: a gestão ambiental em foco: doutrina, jurisprudência, glosário. $6^{\mathrm{a}} \mathrm{Ed}$. rev., atual. eampl. São Pulo: Editora Revista dos Tribunais, 2009.

MORAES. Alexandre de. Direitos Humanos Fundamentais: teoria geral, comentários aos arts. $1^{0}$ a $5^{\circ}$ da Constituição da República Federativa do Brasil, doutrina e jurisprudência. $9^{a}$ ed. São Paulo: Atlas, 2011. p. 27.

PASOLD, Cesar Luiz. Metodologia da pesquisa jurídica: Teoria e prática. $12^{\mathrm{a}}$ ed. São Paulo: Conceito editorial, 2011.

SANTOS, Priscilla Silva. Conservação do Meio Ambiente ou Proteção das Comunidades Tradicionais Indígenas: o Dilema entre Direitos Fundamentais no Direito Ambiental Brasileiro. Revista Magister de Direito Ambiental e Urbanístico. Porto Alegre, v. 41 (abr./mai 2012).

SARLET, Ingo Wolfgang. A eficácia dos direitos fundamentais: uma teoria geral dos direitos fundamentais na perspectiva contitucional. $10^{\mathrm{a}}$ ed. rev. atual. eampl. Porto Alegre: Livraria do Advogado, 2011. 

indígenas. Revista Eletrônica Direito e Política, Programa de Pós-Graduação Stricto Sensu em Ciência Jurídica da UNIVALI, Itajaí, v.11, n.2, 2o quadrimestre de 2016. Disponível em: www.univali.br/direitoepolitica - ISSN 1980-7791.

SILVA, José Afonso da. Direito ambiental constitucional. 6a ed. São Paulo: Malheiros, 2007;

STEFANINI, Luiz de Lima. Código indígena no direito brasileiro. $2^{a}$ ed. Curitiba: Juruá, 2012.

STF. Acórdão da Petição n. 3.388. Relator: Min. Carlos Britto. Tribunal Pleno. Julgado em 19-03-2009. Publicado no DJe em 01-072010.

http://redir.stf.jus.br/paginadorpub/paginador.jsp?docTP=AC\&docID $=612760$. Acesso em 25 de junho de 2014 .

VILAS BOAS, Márcia Cristina Altvater. Os povos indígenas brasileiros e a transição paradigmática: da integração à interação. Porto Alegre: Núria Fabris Ed; 2012.

VILLARES, Luiz Fernando. Direito e povos indígenas. Curitiba: Juruá, 2009.

Submetido em: Dezembro de 2015.

Aprovado em: Junho de 2016. 